\title{
Vulnerabilídade atual e natural à erosão do solo na sub-bacia hidrográíca do Ribeirão Floresta, no município de Cachoeiro de Itapemirim, Espírito Santo, Brasil
}

DOI: $10.20396 /$ labore.v14i0.8659873

\author{
Caio Henrique Ungarato Fiorese \\ $<$ https://orcid.org/0000-0001-6866-0361> \\ Universidade Federal do Espírito Santo / Alegre [ES] Brasil
}

RESUMO

Estudos voltados à erosão dos solos de uma bacia hidrográfica são de extrema importância, principalmente em áreas onde há carência de pesquisas com essa temática, pois auxiliam em diversas tomadas de decisões ambientais. O objetivo deste trabalho foi verificar a erosão atual e potencial na sub-bacia hidrográfica do Ribeirão Floresta (ES), a fim de subsidiar melhorias quanto à conservação dos solos associada a produção econômica. Os procedimentos foram realizados no programa ArcGIS, considerando uma base de dados geográficos. Inicialmente, foi delimitada a sub-bacia. O modelo matemático considerado foi a Equação Universal de Perda de Solos, estimando-se os seguintes dados: erosividade, erodibilidade, comprimento de rampa, declividade e fatores uso e manejo do solo e práticas conservacionistas. Foram estimadas, classificadas e mapeadas as erosões atual e potencial. Quanto à erosão potencial, as classes compreendidas de moderada a muito forte somam 73,98\%, sendo um valor muito expressivo. Há maior tendência natural à erosão na porção norte da BHRF, ao passo que, nas regiões central e sul, predominam intensidades menores. Isso pode ser justificado pelas irregularidades do relevo. Quando somadas, as classes compreendidas de "moderada a alta" a "extremamente alta" correspondem a 48,33\%. Portanto, quase metade está susceptível à perda de solo atual considerando o uso e manejo do solo e práticas conservacionistas, o que pode ser atribuído às formas de ocupação das terras. As áreas naturalmente menos vulneráveis estão ocupadas por atividades que agravam a ocorrência de erosão, ao passo que as áreas potencialmente mais susceptíveis possuem formas de ocupação capazes de proteger o solo. Há necessidade de um melhor planejamento de ocupação da terra através da integração de comitês e gestores públicos com os moradores da sub-bacia. Espera-se que este trabalho contribua para diversas melhorias acerca da conservação dos solos na região.

PALAVRAS-CHAVE

Impactos Ambientais. Manejo da Terra. Recursos Naturais. Sistemas de Informações Geográficas.

\section{Current and natural vulnerability to soil erosion in the Ribeirão Floresta hydrographic sub-basin, in the municipality of Cachoeiro de Itapemirim, state of Espírito Santo, Brazil}

\section{ABSTRACT}

Studies focused on soil erosion in a hydrographic basin are extremely important, especially in areas where there is a lack of research on this theme, as they assist in various environmental decision-making. The objective of this work was to verify the current and potential erosion in the Ribeirão Floresta (ES) hydrographic sub-basin, in order to subsidize improvements in soil conservation associated with economic production. The procedures were performed in the ArcGIS program, considering a geographic database. Initially, the sub-basin was defined. The mathematical model considered was the Universal Soil Loss Equation, estimating the following data: erosivity, erodibility, ramp length, slope and soil use and management factors and conservation practices. Current and potential erosions were estimated, classified and mapped. As for potential erosion, the classes comprised from moderate to very strong add up to $73,98 \%$, being a very expressive value. There is a greater natural tendency to erosion in the northern portion of BHRF, while in the central and southern regions, lower intensities predominate. This can be justified by the irregularities of the relief. When added together, the classes from "moderate to high" to "extremely high" correspond to 48,33\%. Therefore, almost half are susceptible to current soil loss considering the use and management of soil and conservation practices, which can be attributed to the forms of land occupation. The naturally less vulnerable areas are occupied by activities that aggravate the occurrence of erosion, while the potentially more susceptible areas have forms of occupation capable of protecting the soil. There is a need for better planning of land occupation through the integration of committees and public managers with the residents of the sub-basin. It is expected that this work will contribute to several improvements regarding soil conservation in the region.

KEYWORDS

Environmental Impacts. Land Management. Natural Resources. Geographic Information Systems. 


\section{Introducão}

As questões relacionadas à erosão têm aumentado consideravelmente nos últimos anos no Brasil, onde uma parte da população depende de atividades econômicas ligadas à agricultura (Silva, Paiva \& Santos, 2009). A preocupação com o planejamento do uso da terra e a manutenção da qualidade da água e dos remanescentes florestais é um fato a ser enfrentado pela sociedade. Considerando o grande impacto provocado pela agricultura na qualidade e quantidade de tais recursos, ações de mitigação da perda de solo e conservação de recursos são necessários (Miqueloni, Bueno \& Ferraudo, 2012). A degradação dos solos é um problema que influencia todo o mundo e constitui um fenômeno de grande importância, devido à agilidade com que se processa e pelo fato de originar prejuízos expressivos para diversas atividades econômicas e o meio ambiente (Eduardo et al., 2013).

A erosão hídrica do solo, porque provoca a degradação e perda de um recurso natural fundamental para o suporte da vida é, sem dúvida, uma das questões relevantes no campo da gestão ambiental. A medida em que finas camadas de solos vão sendo removidas em espessuras diferentes ao longo de décadas, o processo de erosão progride até atingir um ponto de não retorno, abrindo caminho a um processo de desertificação (Ferreira, 2013). Existem várias formas de erosão provocada pelas águas pluviais, a saber: erosão por salpicamento, erosão laminar, erosão linear (originando sulcos, ravinas e voçorocas), erosão por salpicamento e erosão por solapamento, deslocamento ou escorregamento (Brito, 2012).

Para estudar esse fenômeno, existem metodologias que permitem detetar e diagnosticar sinais precoces e implementar medidas protetoras que reduzam a taxa de erosão (Ferreira, 2013). Por exemplo, existem os chamados métodos diretos, fundamentados na coleta do material erodido, em campos experimentais e/ou em laboratório. Existem, ainda, os métodos indiretos, realizados através de modelagem matemática. Estes modelos podem ser associados às técnicas de geoprocessamento, que permitem análises espaciais das perdas de solo de determinada região, visando o planejamento racional do uso e ocupação do solo e expor as áreas que precisam de adoção de práticas de controle da erosão. Dentre esses modelos, a Equação Universal de Perda de Solos (EUPS), proposta por Wischmeier e Smith (1978). Quando espacializada por meio de um Sistema de Informação geográficas (SIG), permite uma análise da perda de solo por erosão laminar, possibilitando contextualizar os resultados obtidos em função do uso e ocupação das terras (Macedo \& Ruddorf, 2000).

Esta proposição se baseia na junção da aptidão agrícola com o manejo e sua relação com o potencial de erosão dos solos. Estes fatores são relevantes para o processo de manejo sustentável, pois são indicadores na definição de uso do solo, não sendo totalmente relacionados com a produtividade mas com sua preservação (Maciel, 2000). A equação foi elaborada visando prever perdas de solos médias em períodos longos e condições específicas e exprime a ação dos principais fatores que afetam a erosão hídrica, sendo expressa em função de seis variáveis ambientais e de manejo (Ferreira, 2013).

A estimativa e modelagem da erosão do solo é uma ferramenta que auxilia na identificação e classificação de áreas quanto ao risco de erosão, na compreensão dos mecanismos do processo e previsão de cenários, fornecendo informações de apoio para a alocação de recursos e os tipos de práticas que irão fornecer a proteção mais eficaz (Capoane et al., 2013).

As bacias hidrográficas urbanas, semiurbanas e do meio rural reúnem os elementos essenciais para a análise da erosão de solo utilizando a Equação Universal de Perda de Solo, pois as variáveis empregadas neste modelo matemático ficam mais bem representadas e delineadas em âmbito local e regional. Sendo um país de dimensão continental e com grande variedade climática e ecossistêmica, a EUPS, desenvolvida a priori para os Estados Unidos da América (EUA), teve que ser ajustada para a realidade brasileira através de Lombardi Neto e Bertoni (1975) (Pereira, Santos \& Sousa, 2017).

Esta informação fornece subsídios relevantes para a elaboração do planejamento agrícola e ambiental de bacias hidrográficas (Mata et al., 2007). No entanto, a maior limitação ao uso de modelagem matemática para a predição de erosão dos solos consiste na dificuldade em trabalhar com uma grande quantidade de informações que descrevem a heterogeneidade da paisagem. Sendo assim, o uso de Sistemas de Informação Geográficas (SIGs) aliado ao Sensoriamento Remoto, aos Sistemas de Posicionamento Global (GPS) e à Cartografia Digital, torna-se de alta importância para gerar informações que subsidiem estratégias de planejamento visando o uso e o manejo racional do solo (Cemin et al., 2013). A adequação do modelo da EUPS em ambiente computacional de um SIG permite uma otimização e resultados espaciais mais precisos (Mata et al., 2007). 
Portanto, a integração das geotecnologias com os processos ambientais vem sendo realizada com expressivo sucesso em várias partes do mundo. Assim, são de extrema importância para a espacialização, quantificação e gerenciamento dos recursos naturais (Silva, Paiva \& Santos, 2009).

Estudos norteados com recursos de Sistemas de Informações Geográficas associados às análises de perda de solos em determinada região, como uma sub-bacia hidrográfica, são de extrema importância principalmente em áreas onde há carência de pesquisas voltadas à essa temática, como a sub-bacia hidrográfica do Ribeirão Floresta (sigla - BHRF). Sendo assim, o objetivo deste trabalho foi verificar a perda de solo atual e potencial da BHRF, como forma de contribuir para melhorias quanto à conservação dos solos aliada à produção econômica na região.

\section{Material e Métodos}

A sub-bacia hidrográfica do Ribeirão Floresta está localizada no município de Cachoeiro de Itapemirim, na mesorregião Sul do Estado do Espírito Santo. Por ocupar área de zona rural, é uma sub-bacia caracterizada pela predominância de atividades econômicas rurais, como a agricultura e pecuária. Possui seu exutório (local de deságua) no Rio Itapemirim. O bioma predominante na região é a Mata Atlântica, que possui cerca de 20 mil espécies vegetais (com 35\% das espécies existentes no Brasil, aproximadamente), incluindo diversas espécies endêmicas e ameaçadas de extinção. No que concerne à fauna, o bioma abriga em torno de 850 espécies de aves, 370 de anfíbios, 200 de répteis, 270 de mamíferos e 350 de peixes (Brasil, 2020). Esses dados, inclusive, fazem da Mata Atlântica um hotspot mundial, ou seja, um bioma rico em biodiversidade, porém, um dos biomas mais ameaçados do planeta, de acordo com a Associação Mineira de Defesa do Ambiente (AMDA, 2017). A Figura 1 demonstra a localização da região estudada.

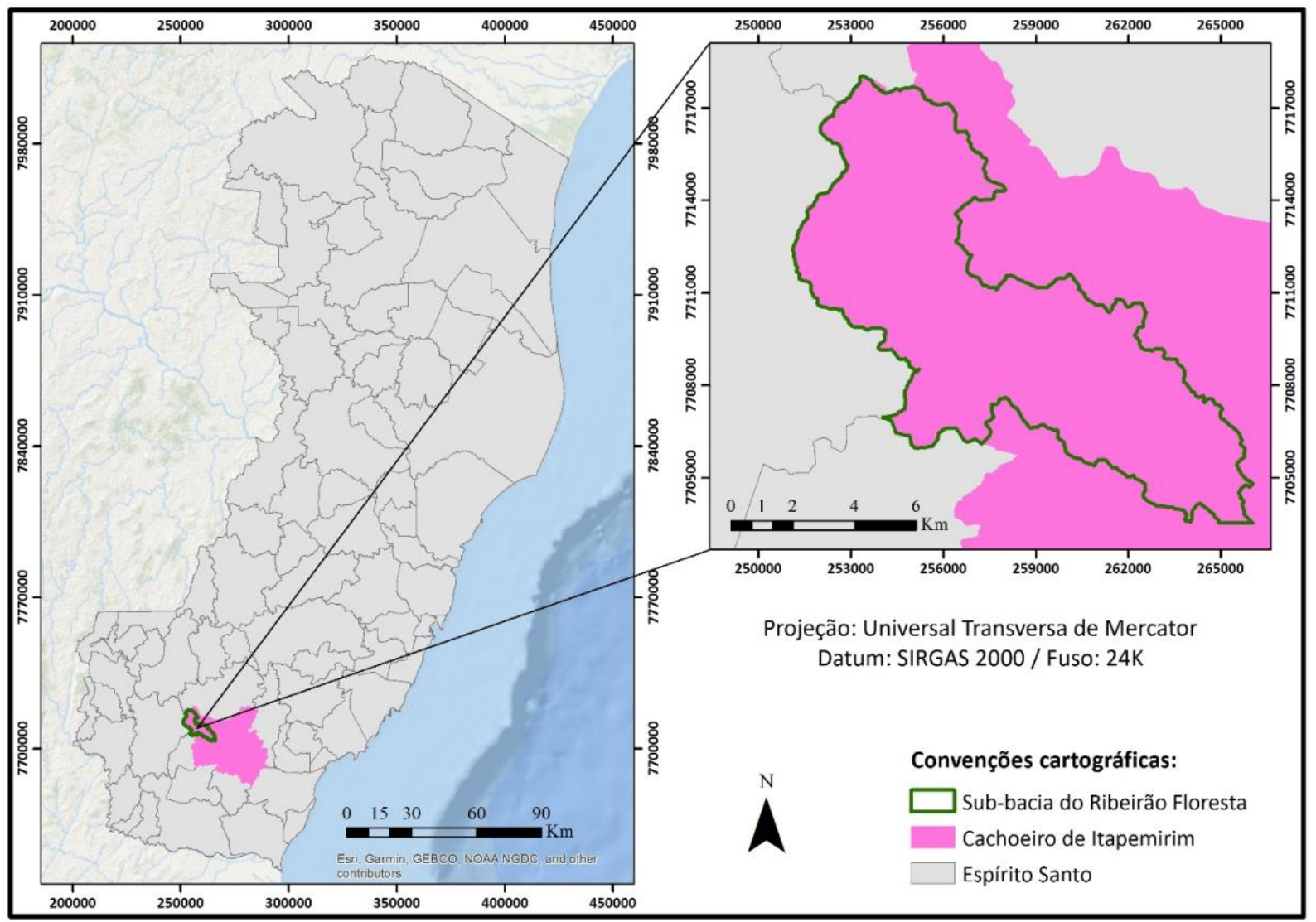

Figura 1. Localização da BHRF. Fonte: O Autor (2020).

Os procedimentos foram executados no programa computacional ArcGIS ${ }$ versão 10.2, tendo como bases cartográficas digitais os sítios eletrônicos do Sistema Integrado de Bases Geoespaciais do Estado do Espírito Santo (Geobases, 2020), da Agência Nacional de Águas (ANA, 2020a) e do Instituto Jones dos Santos Neves (IJSN). Inicialmente, a região de interesse foi identificada a partir de feições de municípios do Estado do Espírito Santo adquiridas junto ao Instituto Jones dos Santos Neves (IJSN, 2020) para, em seguida, delimitar 
a BHRF a partir dos seguintes procedimentos, conforme Santos et al. (2010): aquisição de curvas de nível da região junto ao Geobases e seu posterior recorte para o município de Cachoeiro de Itapemirim; geração do Modelo Digital de Elevação (MDE); correção do MDE (para preencher e corrigir possíveis falhas do MDE gerado); delimitação dos fluxos de direção (flow direction) e de acumulação (flow accumulation) da drenagem; identificação do curso hídrico principal (nesse caso, o Ribeirão Floresta) e do seu exutório (local de deságua da sub-bacia considerada); demarcação do exutório através de um ponto; delimitação da sub-bacia de interesse e; conversão do arquivo representativo da sub-bacia do formato raster para polígono.

A identificação do exutório ocorreu a partir do auxílio de feições de cursos d'água da região adquiridas no portal eletrônico da Agência Nacional de Águas (ANA, 2020a), carregando as informações dos fluxos hídricos e seus respectivos nomes. A Figura 2 representa, resumidamente, um fluxograma com os procedimentos para delimitação da BHRF.

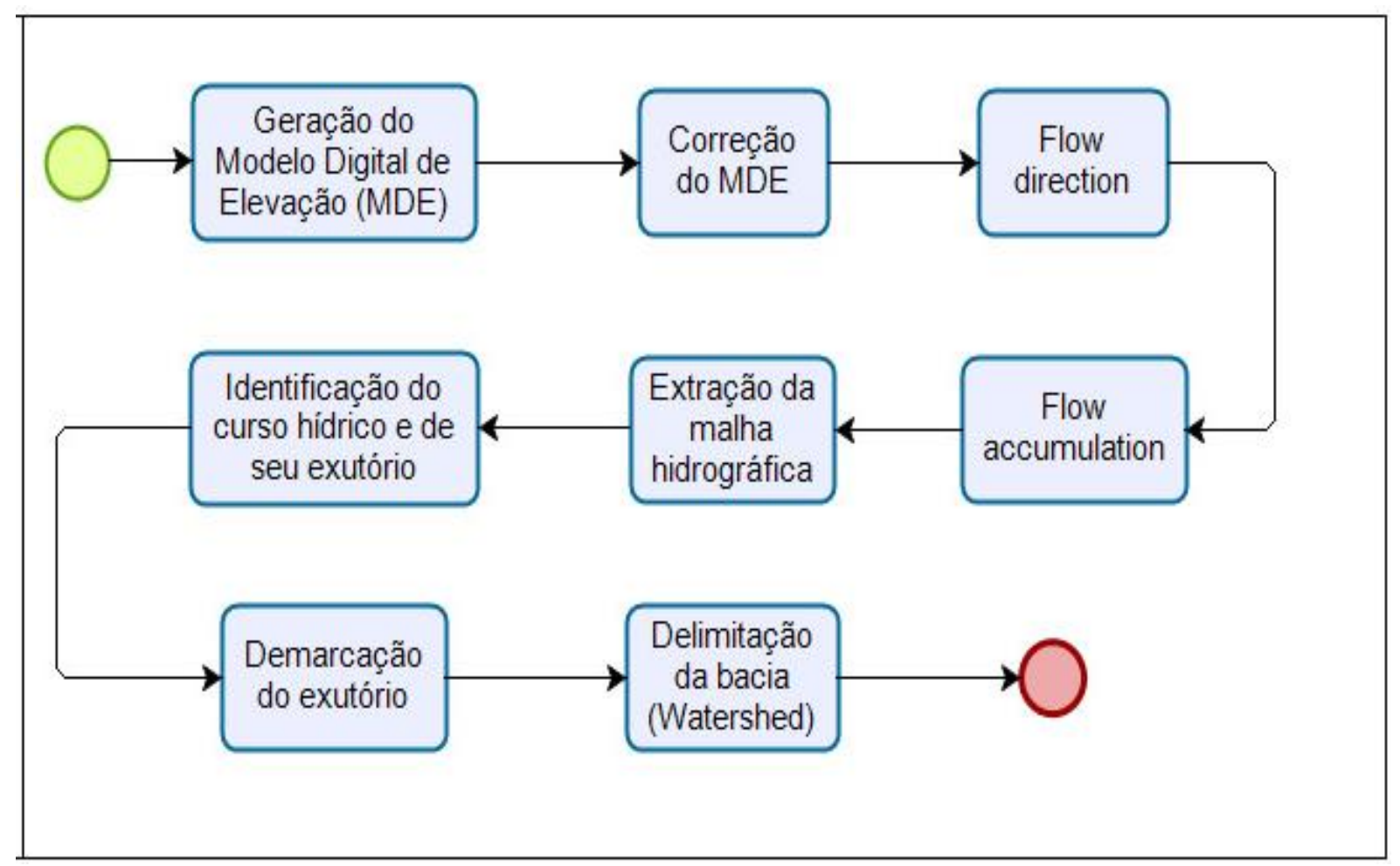

Figura 2. Fluxograma de delimitação da BHRF. Fonte: Adaptado de Santos, Louzada e Eugênio (2010).

Após a delimitação, foi possível dar prosseguimento aos demais procedimentos de avaliação da perda de solos, desta vez para a região de interesse. Para estimar a perda de solos atual e potencial, foi considerada a Equação Universal de Perda dos Solos (EUPS), composta por 6 parâmetros que interferem na intensidade de perda dos solos. Tal modelo matemático é resumido pela equação (1) (Wischmeier \& Smith, 1978):

$$
A=R \times K \times L \times S \times C \times P
$$

Em que: $\mathrm{A}=$ perda de solo $\left(\mathrm{t} \mathrm{ha}^{-1} \mathrm{ano}^{-1}\right) ; \mathrm{R}=$ erosividade da chuva $\left(\mathrm{MJ} \mathrm{ha} \mathrm{hm} \mathrm{h}^{-1} \mathrm{ano}^{-1}\right) ; \mathrm{K}=$ erodibilidade do solo $\left[\mathrm{t} \mathrm{ha} \mathrm{A}^{-1}\left(\mathrm{MJ} \mathrm{ha} \mathrm{mm} \mathrm{h}^{-1}\right)^{-1}\right.$; $\mathrm{L}=$ comprimento do declive (adimensional); $\mathrm{S}=$ grau de declive (adimensional); $\mathrm{C}=$ uso e manejo do solo (adimensional); $\mathrm{P}=$ práticas conservacionistas (adimensional). A erosão atual indica as perdas de solo por erosão hídrica considerando a erosão potencial e as condições atuais de uso do solo e práticas culturais, ou seja, os valores de C e P (Durães \& Mello, 2016). Portanto, a EUPS, considerando todos os seus parâmetros, indica a erosão atual. Já a erosão potencial, causada pelas propriedades físicas da região estudada, inclui apenas os parâmetros R, K, L e S.

A capacidade da chuva de causar erosão em uma área sem proteção em uma dada localidade é expressa pelo fator numérico R (Wischmeier \& Smith, 1962), que deve ser calculado a partir de índices mensais de erosão, obtidos pela equação (2), desenvolvida por Lombardi Neto \& Moldenhauer (1992):

$$
\text { EI } i=67,355 \times\left(\frac{\mathrm{ri}^{2}}{\mathrm{Pi}^{2}}\right)^{0,85}
$$


Em que: EI i = média mensal do índice de erosão $\left(\mathrm{MJ} \mathrm{ha} \mathrm{hm}^{-1} \mathrm{~mm}^{-1}\right.$; ri = precipitação pluvial média mensal, em $\mathrm{mm} ; \mathrm{Pi}=$ precipitação pluvial média anual, em mm. O fator $\mathrm{R}$ corresponde ao somatório dos índices mensais de erosão (Bertoni \& Lombardi Neto, 1999). Os dados de precipitação foram adquiridos junto ao portal eletrônico Hidroweb, da Agência Nacional de Águas (Ana, 2020b), referentes a uma estação pluviométrica localizada no município de Cachoeiro de Itapemirim, Estado do Espírito Santo, com uma série histórica de 55 anos. A estação apresentou as seguintes coordenadas geográficas: S 20 40' 50.16" e W 41²0' 53.88". Foi considerada essa estação devido à ampla série histórica pluviométrica existente.

Através do MDE da área estudada, foi gerado o mapa de declividade, em graus, através da função "slope" no ArcGIS, para determinar os fatores L e $\mathrm{S}$ da EUPS. $\mathrm{Na}$ prática, esses dois fatores são considerados conjuntamente, por meio de um termo denominado fator topográfico ou LS, que é obtido a partir da agregação do comprimento das encostas (vertentes) com o gradiente de declividade (grau de inclinação), por meio de modelos matemáticos (Galdino, 2012). Os fatores comprimento de rampa e declividade, embora têm sido pesquisados separadamente, é mais conveniente considerá-los conjuntamente como um fator LS (Bueno et al., 2011). O fator LS interfere na dinâmica erosiva por meio do comprimento da vertente e da inclinação do relevo, que são fatores fundamentais para compreender o processo de escoamento superficial da água (Pinheiro \& Cunha, 2011).

O fator topográfico (LS) da equação foi obtido a partir da geração de dois mapas. O mapa do fator L foi obtido com auxílio da metodologia proposta por Desmet \& Govers (1996), McCool et al. (1987) e McCool et al. (1989), através das equações (3), (4) e (5).

$$
\begin{aligned}
& F=\frac{\sin C / 0,0896}{0,56+3(\sin C)^{0,8}} \\
& m=\frac{F}{1+F^{\prime}} \\
& L=\frac{\llbracket A+D^{2} \rrbracket^{(m+1)}-A^{m+1}}{x^{m} D^{m+2}(22,13)^{m}}
\end{aligned}
$$

Em que: $\mathrm{D}$ = tamanho do pixel; $\mathrm{A}$ = fluxo acumulado da drenagem (obtido no ArcGIS®, a partir do MDE da área e da posterior obtenção da direção do fluxo de drenagem); $\mathrm{C}=$ declividade (expressa e convertida em radianos); $\mathrm{x}=$ coeficiente de forma (adotado $\mathrm{x}=1$, para sistemas compostos por pixels); $\mathrm{m}, \mathrm{F}=$ coeficientes (adimensional).

Em seguida, foi gerado o mapa do fator S, pelo algoritmo de McCool et al. (1987) e McCool et al. (1989), partindo das seguintes condições, considerando a declividade: quando $\tan \mathrm{C}<0,09$, adotar $\mathrm{S}=10,8 \sin (\mathrm{C})+$ 0,03 e; quando $\tan C \geq 0,09$, adotar $S=16,8 \sin (C)+0,5$.

Alguns solos apresentam maior propensão à erosão que outros, mesmo quando a cobertura vegetal, a precipitação, o declive e as práticas de controle de erosão são as mesmas. Essa diferença é chamada de erodibilidade do solo (fator K), e ocorre devida às propriedades inerentes ao solo (Bertoni \& Lombardi Neto, 1999). Esse parâmetro significa a vulnerabilidade ou suceptibilidade à erosão do solo, que é a recíproca da sua resistência à erosão. A erodibilidade é a única variável, na EUPS, relacionada com as características do solo, estando relacionada com as interações físico-químicas, biológicas e mineralógicas do solo. (Ahmed, 2009). O fator K (erodibilidade do solo) foi determinado inicialmente, a partir do mapeamento dos tipos de solos da BHCP e, em seguida, pela consulta dos dados na literatura.

Os fatores C (uso e manejo do solo) e P (práticas conservacionistas), assim como o fator topográfico, também foram considerados de forma conjunta e estão inerentes às formas de uso e ocupação da BHRF. O fator C representa um índice que determina o quanto cada espécie de cobertura vegetal oferece de proteção ao solo ao longo de diferentes épocas do ano (Souza \& Gasperetto, 2012). Já o fator P relaciona a intensidade de perdas de solo com uma determinada prática conservacionista e as perdas quando a cultura esta plantada no sentido do declive, ou seja, morro abaixo (Wischmeier \& Smith, 1978). 
Os dados do fator CP foram consultados na literatura abordada, para cada forma de uso e ocupação do solo que, por sua vez, foi identificado a partir de feições referentes ao uso e ocupação do solo do Estado do Espírito Santo adquiridas no portal eletrônico do GEOBASES, acerca do mapeamento realizado nos anos de 2012 a

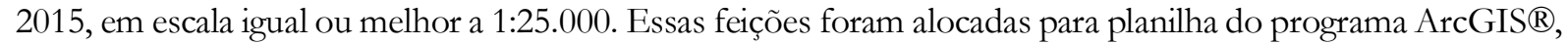
tornando-se possível, através dos recursos de edição de arquivos, a delimitação do uso e ocupação somente para a sub-bacia de interesse. Após consultar na literatura os números do fator CP, os mesmos foram inseridos na tabela de atributos do novo arquivo de uso e ocupação gerado (para a BHRF).

A inserção de todas as equações foi feita na ferramenta "raster calculator", também conhecida como álgebra de mapas, que permite trabalhar com mapas a partir das equações inseridas no programa ArcGIS. O tamanho dos pixels adotado para este trabalho foi de 10, pois esse seria o mais adequado para áreas menores, como foi o caso da sub-bacia estudada. Após a obtenção de todos os componentes da equação, as informações quantitativas e geoespacializadas das erosões atual e potencial foram classificadas conforme a metodologia de Beskow et al. (2009), apresentada nas Tabelas 1 e 2.

Tabela 1. Classes de intensidade à erosão potencial. Fonte: Beskow et al. (2009).

\begin{tabular}{|l|l|}
\hline Classes de intensidade & Faixa quantitativa (ton/ha.ano) \\
\hline Fraca & $\leq 400$ \\
\hline Moderada & $400-600$ \\
\hline Moderada a forte & $600-1.600$ \\
\hline Forte & $1.600-2.400$ \\
\hline Muito forte & $>2.400$ \\
\hline
\end{tabular}

Tabela 2. Classes de intensidade à erosão atual. Fonte: Beskow et al. (2009).

\begin{tabular}{|l|l|}
\hline Classes de intensidade & Faixa quantitativa (ton/ha.ano) \\
\hline Ligeira & $\leq 2,5$ \\
\hline Ligeira a moderada & $2,5-5$ \\
\hline Moderada & $5-10$ \\
\hline Moderada a alta & $10-15$ \\
\hline Alta & $15-25$ \\
\hline Muito alta & $25-100$ \\
\hline Extremamente alta & $>100$ \\
\hline
\end{tabular}

\section{Resultados e discussão}

A erosividade estimada (fator R) para a BHRF foi igual a 7.516,91 $\mathrm{MJ} \mathrm{ha}^{-1} \mathrm{~mm}^{-1}$. Esse valor pode ser classificado como "forte", segundo a classificação de Carvalho (2008). Quanto à erodibilidade (fator K) determinada, foram observados dois tipos de solos diferentes: argissolo vermelho, com percentual de ocupação na sub-bacia igual a a 48,82\% e fator K equivalente a 0,044; e neossolo litólico, com percentual de 51,18\% e fator $\mathrm{K}$ igual a 0,048. A sub-bacia estudada também possui nove tipos diferentes de solos, com valores de fator CP (uso e manejo do solo e práticas conservacionistas) que variam de 0 a 1 , conforme a literatura consultada. A Tabela 3 apresenta, em detalhes, os valores de CP adotados para cada classe de uso e ocupação.

Tabela 3. Dados do fator CP para cada uso e ocupação de solo. Fonte: Stein et al., 1987; Silva, 2004; Martins et al., 2010.

\begin{tabular}{|l|c|}
\hline Classe (uso e ocupação do solo) & Fator CP \\
\hline Afloramento rochoso & 0 \\
\hline Área edificada & 0 \\
\hline Brejo & 0 \\
\hline Campo rupestre/altitude & 0,01 \\
\hline Cultivo agrícola - banana & 0,25 \\
\hline Cultivo agrícola - café & 0,25 \\
\hline Cultivo agrícola - coco-da-baía & 0,25 \\
\hline Outros cultivos permanentes & 0,25 \\
\hline Outros cultivos temporários & 0,20 \\
\hline Extração (Mineração) & 0 \\
\hline Macega & 0,01 \\
\hline Massa d'água & 0 \\
\hline
\end{tabular}




\begin{tabular}{|l|c|}
\hline Vegetação nativa & 0,00013 \\
\hline Vegetação nativa em estágio inicial de regeneração & 0,00013 \\
\hline Outras classes & 0 \\
\hline Pastagem & 0,025 \\
\hline Reflorestamento - eucalipto & 0,0026 \\
\hline Solo exposto & 1 \\
\hline
\end{tabular}

Foram, portanto, identificadas dezoito classes diferentes de uso e ocupação. Percebe-se que os valores do fator $\mathrm{CP}$ variam conforme o uso e manejo da terra, sendo os maiores valores associados aos passivos ambientais, capazes de causar maior perda de sedimentos. O valor zero está associado as áreas urbanas e aos corpos hídricos. Já os menores valores são interligados à vegetação remanescente, sendo considerada a cobertura mais densa (Lima, Ferreira \& Ferreira, 2018). No caso da BHRF, os menores valores estão associados às classes "vegetação nativa" e "vegetação nativa em estágio inicial de regeneração". O valor 1, por sua vez, está associado a classe "solo exposto", sendo, portanto, a classe capaz de provocar a maior perda de solos na sub-bacia estudada.

Após a obtenção do fator topográfico (LS), foi possível estimar as perdas de solo atual e potencial. Em relação à erosão potencial, a maior classe de intensidade foi vista para a "moderada a forte", com perdas que variam de 600 a 1.600 ton/ha.ano, ao passo que a classe com menor abrangência foi para a "moderada", com apenas 6,02\% da área da BHRF e com perdas de solos menores ou iguais a 400 ton/ha.ano. A Tabela 4 e a Figura 3 apresentam, respectivamente e em detalhes, os dados de área, em quilômetros quadrados $\left(\mathrm{Km}^{2}\right)$ e em porcentagem (\%), para cada intensidade de perda potencial de solos e o mapa temático de intensidade da erosão potencial.

Tabela 4. Área e percentuais de abrangência para cada classe de intensidade de erosão potencial. Fonte: O Autor (2020).

\begin{tabular}{|l|c|c|}
\hline Classes (ton/ha.ano) & Área $\left(\mathrm{Km}^{2}\right)$ & Área (\%) \\
\hline Fraca $(\leq 400)$ & $17,19 \mathrm{Km}^{2}$ & $20,00 \%$ \\
\hline Moderada $(400-600)$ & $5,17 \mathrm{Km}^{2}$ & $6,02 \%$ \\
\hline Moderada a forte $(600-1.600)$ & $35,91 \mathrm{Km}^{2}$ & $41,79 \%$ \\
\hline Forte $(1.600-2.400)$ & $19,71 \mathrm{Km}^{2}$ & $22,94 \%$ \\
\hline Muito forte $(>2.400)$ & $7,95 \mathrm{Km}^{2}$ & $9,25 \%$ \\
\hline
\end{tabular}

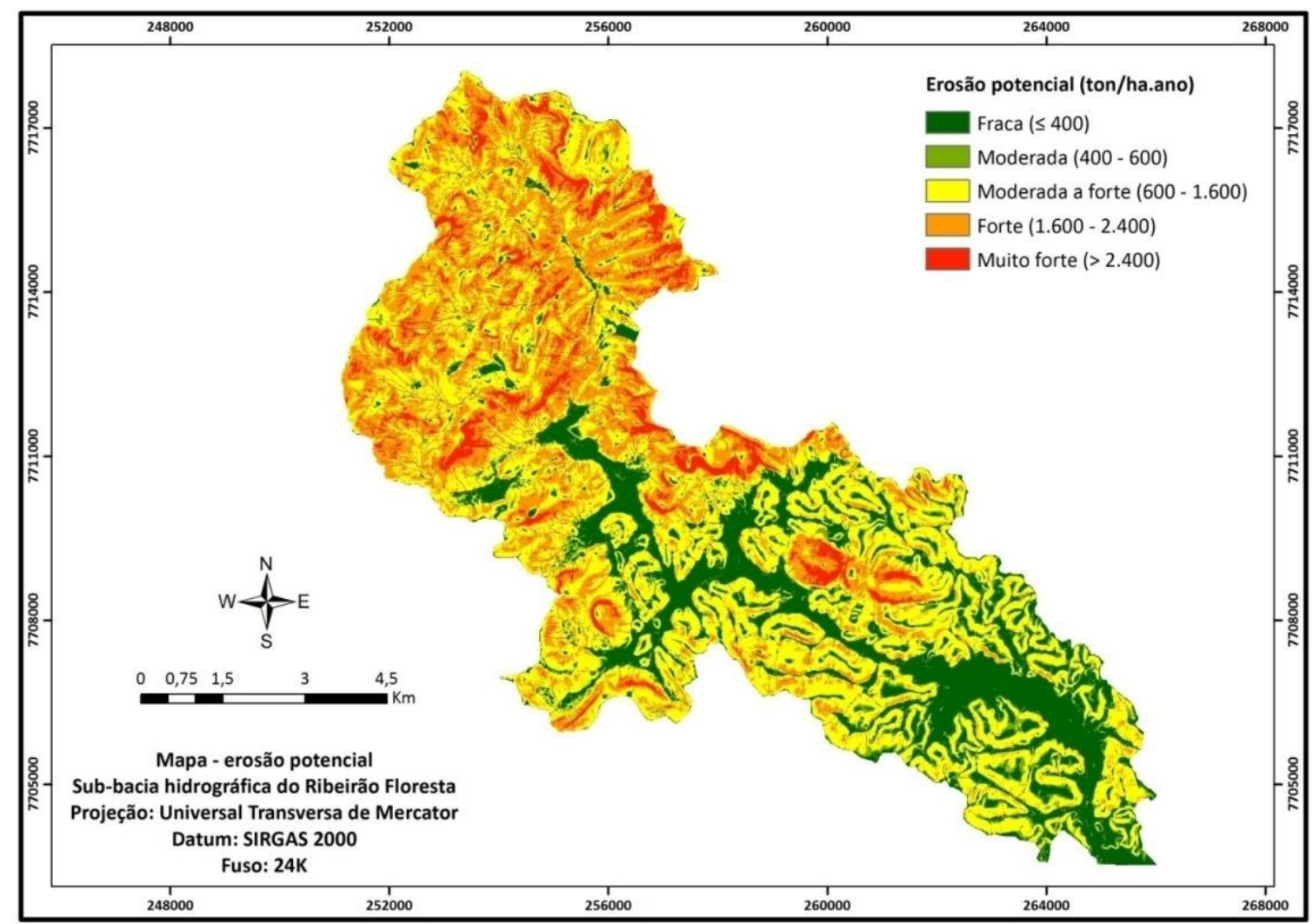

Figura 3. Mapa de erosão potencial. Fonte: O Autor (2020). 
Verifica-se que as classes compreendidas de moderada a muito forte somam $73,98 \%$ da sub-bacia, ou seja, representa um valor muito expressivo. Além do mais, há maior tendência natural à erosão na porção norte da BHRF, ao passo que, nas regiões central e sul, predominam intensidades menores de tendência à erosão. A alta representatividade das classes de maior intensidade pode estar relacionada, principalmente, às irregularidades do relevo da região da BHRF. A influência do relevo na intensidade erosiva é vista, principalmente, pela declividade e comprimento de rampa, da encosta ou vertente. Ambas interferem diretamente na velocidade de escoamento superficial da água das chuvas. Os terrenos mais declivosos e com maiores comprimentos de rampa apresentam grandes velocidades de escoamento superficial e, por consequência, maior capacidade erosiva. Porém, uma encosta com baixa declividade e comprimento de rampa grande também pode apresentar alta intensidade de erosão, desde que exposta à grande vazão de escoamento hídrico superficial (Infanti Junior \& Fornasari Filho, 1998). Gurgel et al. (2011), em seus estudos acerca da vulnerabilidade ambiental do município de Riachão das Neves (BA), constataram que as áreas mais vulneráveis estão dispostas em locais de maior declividade. Sendo assim, a declividade é um dos fatores que potencializam a perda de solos na BHRF, sobretudo na porção norte desta sub-bacia. Outro fator relevante é o comprimento de rampa, pois a energia de escoamento superficial tende a se concentrar e ser mais elevada nas rampas mais longas, fazendo com que a enxurrada gere elevado número de sulcos (formações erosivas) (Ahmed, 2009).

O fator topográfico, que constitui nos parâmetros anteriormente discutidos, possui grande influência na Equação Universal da Perda de Solos, pois assume maior influência em comparação com as outras variáveis consideradas, mesmo levando em conta o aumento do fator práticas conservacionistas (Pereira et al., 2014). Dessa forma, a tendência natural à perda de solos na BHRF pode estar mais relacionada aos fatores comprimento de rampa e declividade. As áreas mais susceptíveis a erosões intensas, caso as atividades antrópicas não sejam planejadas e manejadas corretamente, podem desencadear sérios problemas ambientais. A erosão hídrica intensa impacta diversas atividades humanas, como a agricultura, o transporte fluvial, a pesca, a geração de energia elétrica, etc. $\mathrm{O}$ aumento da taxa de erosão em uma bacia hidrográfica, por exemplo, provoca assoreamento de corpos hídricos (Matos, 2015). Nesse sentido, Costa \& Silva (2012) propõem a adoção de práticas conservacionistas através do uso de ferramentas que rescindam o comprimento da rampa e diminuam o espaço de escoamento superficial da água, a fim de atenuar a tendência natural à perda de solos.

Para mitigar essa tendência à perda de solos, podem ser utilizadas técnicas conservacionistas que tenham os seguintes objetivos: interceptar o escoamento superficial da água das chuvas, reter e disciplinar as águas de escoamento com velocidade com potencial não erosivo e deter as partículas de solo transportadas pela plúviosidade antes de que as mesmas sejam incorporadas aos leitos de cursos hídricos (Gomes, 2001). Além do mais, nas áreas naturalmente mais vulneráveis da BHCF, é de grande importância a manutenção da vegetação. A cobertura vegetal protege o solo contra a erosão pluvial, aumentando a evapotranspiração e a infiltração, diminuindo o escoamento. Ela impede que parte da água da chuva não chegue ao solo, sendo interceptada pela folhagem e evapora diretamente.Outra parte se escoa vagarosamente pelos ramos e troncos, indo ao solo para se infiltrar (Ahmed, 2009). A vegetação forma uma barreira física ao transporte de matérias (sobretudo as plantas rasteiras), diminuindo a velocidade de escoamento da água. (Bertoni \& Lombardi Neto, 2005). Assim, a manutenção da cobertura vegetal nas áreas de maior intensidade natural à erosão laminar, além dos benefícios à fauna e flora, contribui para a conservação de outros recursos naturais, como a água, e influi em uma melhor produtividade econômica para os produtores rurais desta região. Nesse sentido, Gurgel et al. (2011) propõem a manutenção de uma faixa de preservação em locais mais declivosos. Sugestão essa relevante para a BHRF, considerando a sua elevada potencialidade à perda de solos.

Para o planejamento territorial, uma das informações mais requisitadas é a vulnerabilidade natural à perda de solo. No decreto de lei número 4297, de junho de 2002, que estabelece os critérios mínimos para a elaboração do Zoneamento Ecológico e Econômico do Brasil (ZEE), é salientada a necessidade de obterindicadores da vulnerabilidade natural à perda de solo como um atributo integrante para delimitar a Fragilidade Natural Potencial (Borges et al., 2002).

As estimativas de erosão potencial ou potencial natural de erosão (PNE) podem contribuir, ainda, para restringir o uso e ocupação de áreas potencialmente vulneráveis à erosão. Isso evita, por exemplo, a oneração de custos de infraestrutura, que são patologias em obras da construção civil. Deve-se trazer a atenção dos planejadores e autoridades locais para as regiões mais frágeis, com relevo irregular. Nestas áreas, precisam ser estabelecidos programas de combate, controle e prevenção da erosão, não descartando a possibilidade de adoção de novas alternativas de uso menos intensivas (Pedro \& Lorandi, 2004). Por isso, espera-se que 
os resultados observados sobre a erosão potencial da BHRF sejam utilizados para um planejamento correto das atividades antrópicas, de forma a conciliar a conservação dos solos com a produtividade econômica na área rural com base nos conhecimentos acerca da potencialidade de cada área no que concerne à erosão natural.

A Tabela 5 e a Figura 4 indicam, respectivamente, os percentuais de abrangência de cada classe de erosão atual e a geoespacialização dessa erosão. Verifica-se que a classe de erosão mais abrangente foi a "ligeira” (49,03\%), o que significa um excelente percentual visando minimizar às perdas naturais de solo. Todavia, a classe "extremamente alta" abrange uma área expressiva de 37,15\%, conforme mostrado na Tabela 5.

Tabela 5. Percentuais de abrangência para cada classe de intensidade de erosão atual. Fonte: O Autor (2020).

\begin{tabular}{|l|c|c|}
\hline Classes (ton/ha.ano) & Área $\left(\mathrm{Km}^{2}\right)$ & Área (\%) \\
\hline Ligeira $(\leq 2,5)$ & $42,13 \mathrm{Km}^{2}$ & $49,03 \%$ \\
\hline Ligeira a moderada $(2,5-5)$ & $1,42 \mathrm{Km}^{2}$ & $1,66 \%$ \\
\hline Moderada $(5-10)$ & $0,84 \mathrm{Km}^{2}$ & $0,98 \%$ \\
\hline Moderada a alta $(10-15)$ & $1,22 \mathrm{Km}^{2}$ & $1,42 \%$ \\
\hline Alta $(15-25)$ & $2,34 \mathrm{Km}^{2}$ & $2,72 \%$ \\
\hline Muito alta $(25-100)$ & $6,05 \mathrm{Km}^{2}$ & $7,04 \%$ \\
\hline Extremamente alta $(>100)$ & $31,84 \mathrm{Km}^{2}$ & $37,15 \%$ \\
\hline
\end{tabular}

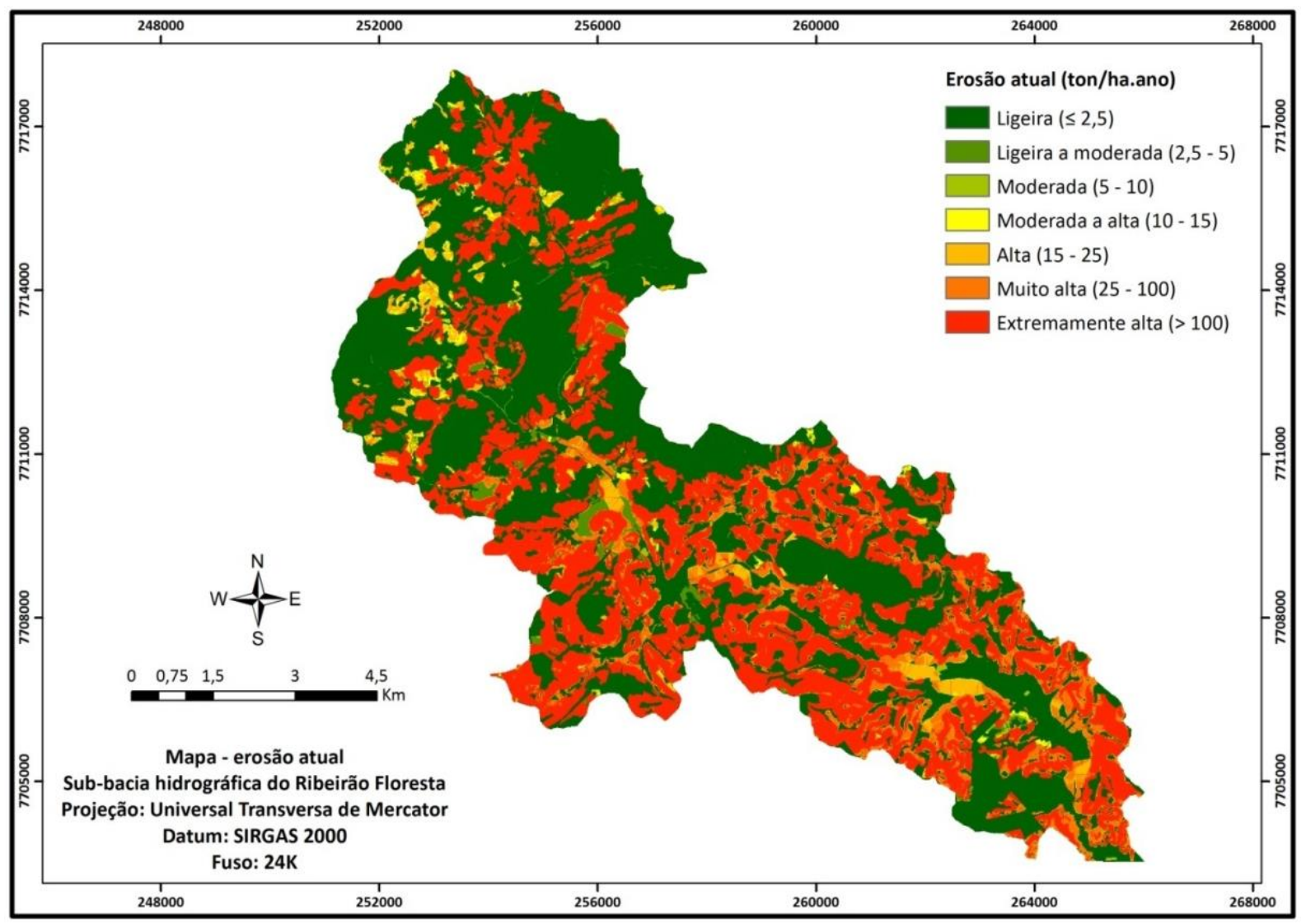

Figura 4. Mapa de erosão potencial. Fonte: O Autor (2020).

A Figura 4, portanto, evidencia praticamente o oposto visto no mapeamento da erosão potencial, pois as áreas mais vulneráveis à erosão, considerando o manejo de solos e práticas conservacionistas, ficam localizadas, em sua maioria, nas porções central e sul da BHRF. Já as áreas com menores índices de erosão atual estão expostas, em sua maioria, na porção norte desta sub-bacia. Conforme a Tabela 5, quando somadas, as classes compreendidas de "moderada a alta" a "extremamente alta" correspondem a 48,33\%, ou seja, quase metade da BHRF está susceptível à perda de solo atual considerando o uso e manejo do solo e práticas conservacionistas. Isso pode ser atribuído às formas de ocupação das terras, pois as áreas naturalmente menos vulneráveis à perda de solos estão ocupadas por atividades que contribuem significamente para a ocorrência desse problema, ao passo que as áreas potencialmente mais susceptíveis possuem formas de ocupação capazes de proteger o solo, como é o caso da vegetação nativa. 
A vegetação forma um bloqueio físico ao carreamento de matérias (principalmente as plantas rasteiras). Ela reduz a velocidade de escoamento das águas, de forma com que, quando a velocidade é reduzida à metade, o transporte cai a quarta parte de seu valor (Bertoni \& Lombardi Neto, 2005). Portanto, nas áreas naturalmente mais vulneráveis à perda de solos, a baixa perda de solos provavelmente está atrelada à presença de coberturas florestais mais densas, como é o caso da vegetação nativa. As classes presentes na porção norte da sub-bacia são capazes de conter expressivamente a tendência natural à perda de solos, o que significa um fator positivo quanto à qualidade dos recursos naturais.

No entanto, a situação descrita na porção norte da BHRF não é a mesma em muitos outros locais. Isso é reflexo da maior ocupação antrópica nesses locais, que pode ser justificada pelas condições topográficas e de relevo. A ocupação humana, a princípio comandada pelo desmatamento e seguida pelo cultivo da terra, pela construção de estradas, criação e expansão das vilas e cidades, sobretudo quando concretizada de forma inadequado, constitui fator decisivo da origem e aceleração dos processos erosivos, sendo deflagrados pela ocupação do solo (Ahmed, 2009). Algumas consequências são acarretadas pelo mau planejamento das atividades antrópicas e potencialidades nas formas de erosão dos solos, como, por exemplo, a alteração da morfodinâmica e das formas de relevo. Em termos sociais, pode trazer prejuízos econômicos e, até mesmo, afetar a qualidade de vida humana (Silva et al., 2015). Portanto, a potencialidade agravada pelo uso e manejo dos solos na BHRF pode culminar nos problemas ambientais supracitados. Por isso, há necessidade de reduzir os percentuais de forte intensidade a perda de solos, o que é possível apenas na colaboração dos produtores rurais da região e outros moradores associada à indispensável assistência de gestores públicos e comitê de bacia hidrográfica local, em prol de exercer atividades mais sustentáveis e conservacionistas em termos de qualidade dos solos e dos outros recursos naturais presentes ali.

A utilização adequada das terras agrícolas é de extrema importância, pois minimiza os problemas já existentes e mantém o potencial das terras ainda intactas. Na utilização de uma gleba, geralmente são empregados diversos manejos e culturas. A cultura, nos diferentes graus de desenvolvimento, oferece diferentes graus de proteção, podendo levar a diferenças em perdas de solo, juntamente com a incidência dos fatores climáticos, a resistência dos solos e o manejo dos restos culturais (Bueno \& Stein, 2004). Segundo Mota (1981), as atividades agrícolas precisam ser desenvolvidas considerando várias medidas de mitigação e atenuação da perda de solos, tais como: nos terrenos em encostas: plantio em curvas de nível e o cultivo em terraços combinado com o plantio em contorno e preservação d vegetação nativa nas partes mais altas; nos espaços de vegetação permanente, como é o caso dos topos de morro, áreas com declividade maior ou igual a 45 graus e faixas de cursos d'água: implantar barreiras de cobertura vegetal, no intuito de reter o escoamento, facilitar a deposição de sedimentos e a infiltração da água; controle de queimadas; praticar a rotação de culturas e sua diversificação; manutenção da cobertura morta do solo; adubação orgânica e; implantação de cobertura verde, que significa o emprego de plantas que geram grandes quantidades de biomassa em pouco tempo, sendo cortadas ainda verdes e enterradas. No caso da pecuária, é relevante a adoção de técnicas que visam à drenagem das águas pluviais, a fim de reduzir os impactos dessa atividade em termos de erosão laminar. Além do mais, o emprego de recursos de caráter conservacionista, como é o caso dos chamados Sistemas Silvipastoris, que consistem no emprego de vários indivíduos arbóreos e/ou arbustivos dentro de uma área de pasto (Ribaski et al., 2005), o que traria maior proteção ao solo. Portanto, tais sugestões são indispensáveis para as áreas da BHRF, mesmo aquelas com baixa susceptibilidade a perdas de solo, tendo em vista a presença de atividades agropecuárias na região e o elevado percentual da classe de intensidade "extremamente alta" de perda de solos.

\section{Conclusão}

A sub-bacia possui elevada tendência à erosão atual praticamente em sua metade, devido às formas de uso e ocupação da terra e práticas conservacionistas, principalmente nas porções central e sul. Já a tendência natural à perda de solos é praticamente maior na porção norte da sub-bacia e menor nas demais áreas, se opondo à vulnerabilidade à erosão quando se considera os fatores uso e manejo e práticas conservacionistas. Tal fato está atrelado às condições topográficas e de relevo embutidas na Equação Universal de Perda dos Solos, principalmente os parâmetros comprimento de rampa e declividade.

Portanto, há necessidade de ações voltadas à mitigação e atenuação da erosão como, por exemplo, utilização de práticas conservacionistas na agropecuária e um melhor planejamento de ocupação da terra por meio da integração de comitês e gestores públicos com os moradores da região da BHRF, a fim de mitigar e atenuar a erosão atual e potencial. Espera-se, ainda, que os estudos deste trabalho sejam capazes de alavancar outras pesquisas na região atreladas ao planejamento natural e antrópico e que, de fato, sirvam para o subsídio para, além das ações argumentadas, diversas outras melhorias no que tange à conservação dos solos na BHRF. 


\subsection{AgRADECIMENTOS}

O autor agradece à Fundação de Amparo à Pesquisa e Inovação do Espírito Santo - FAPES, pelo suporte financeiro e estrutural para a realização desta pesquisa.

\section{Reierências}

Ahmed, C. R. M. (2009). Fatores que influenciam a erodibilidade nos solos do município de Campos dos Goytacazes-RJ sob uma análise multicritério. Dissertação (Mestrado em Engenharia Civil) Centro de Ciência e Tecnologia, Universidade Estadual do Norte Fluminense Darcy Ribeiro, Campos dos Goytacazes, RJ, Brasil.

AMDA - Associação Mineira de Defesa do Ambiente (2017). Mata Atlântica é hotspot mundial. Recuperado 12 de feveiro de 2020, de https://www.amda.org.br/index.php/comunicacao/informacoes-ambientais/5229-mata-atlantica-ehotspot-mundial.

ANA - Agência Nacional de Águas (2020a). Encontre mapas interativos, conjuntos de dados geográficos, imagens de satélite e outros serviços. Recuperado 12 de março de 2020, de https://metadados.ana.gov.br/geonetwork/srv/pt/ma in.home

ANA - Agência Nacional de Águas (2020b). Séries históricas de estaçoes. Recuperado 12 de março de 2020, de http://www.snirh.gov.br/hidroweb/serieshistoricas

ArcGIS (2020). ArGIS: software. Recuperado 10 de janeiro de 2020, de http://www.esri.com/software/arcgis/ind ex.html

Bertoni, J., \& Lombardi Neto, F. (1999). Conservação do solo. 4. ed. São Paulo: Ícone Editora.

Bertoni, J., \& Lombardi Neto, F. (2005). Conservação do Solo. 5.ed. São Paulo: Ícone Editora. 355p.

Beskow, S., Mello, C. R., Norton, L. D., Curi, N., Viola, M. R., \& Avanzi, J. C. (2009). Soil erosion prediction in the Grande River Basin, Brazil using distributed modeling. Catena, 79(1), 49-59.

Borges, K. M. R., Carvalho Júnior, O. A., Martins, E. S., Gomes, R. A. T., \& Guimarães, R. F. (2012). Vulnerabilidade natural: a perda de solo da bacia do Rio Carinhanha (MG/BA) usando uma abordagem qualitativa da Equação Universal de Perda de Solos. Geographia, 14 (27), 101-125. https://doi.org/10.22409/GEOgraphia2012.v14i27.a13636

Brasil. Ministério do Meio Ambiente. Mata Atlântica. Recuperado 11 de março de 2020, de https://www.mma.gov.br/biomas/mata-atl\%C3\%A2ntica_emdesenvolvimento

Bueno, C. R. P., \& Stein, D. P. (2004). Potencial natural e antrópico de erosão na região de Brotas, Estado de São Paulo. Acta Scientiarum, 26 (1), 1-5. https://doi.org/10.4025/actasciagron.v26i1.1946

Capoane, V., Santos, L. J. C., Minella, J. P. G., Tiecher, T., \& Trentin, R. (2013). Determinação do fator topográfico utilizando Modelos Digitais de Elevação de diferentes fontes e resoluções para a Bacia Hidrográfica do Rio Conceição - RS. Recuperado 3 de abril de 2020, de http://marte2.sid.inpe.br/col/dpi.inpe.br/marte2/2013/05.28.23.59/doc/p0795.pdf

Carvalho, N. O. (2008). Hidrossedimentologia prática. 2.ed. Rio de Janeiro: Interciência.

Cemin, G., Périco, E., Schneider, V. E., \& Finotti, A. R. (2013). Determinação da perda de solos por erosão laminar na bacia hidrográfica do arroio Marrecas, RS, Brasil. Scientia Plena, 9 (1), 1-9.

Costa, S. G. F., Silva, R. M. da, \& Silva, R. M. da (2012). Potencial natural e antrópico de erosão na bacia experimental do Riacho Guaraíra. Cadernos do Longepa, 7 (1), 72-91.

Durães, M. F., \& Mello, C. R. de (2016). Distribuição espacial da erosão potencial e atual do solo na Bacia hidrográfica do Rio Sapucaí, MG. Engenharia Sanitária e Ambiental, 21 (4): 677-685.

Eduardo, E. N., Carvalho, D. F. de, Machado, R. L., Soares, P. F. C., \& Almeida, W. S. de (2013). Erodibilidade,fatores cobertura e manejo e práticas conservacionistas em argissolo vermelho-amarelo, sob condições de chuva natural. Revista Brasileira de Ciência do Solo, 37: 796-803.

Ferreira, C. (2013). O mundo (im) perfeito dos modelos de erosão. Revista da Faculdade de Letras - Geografia, 2(3): 51-82

Geobases. (2020). IEMA - mapeamento ES - 2012-2015. Recuperado 12 de março de 2020, de https://geobases.es.gov.br/links-para-mapes1215

Gomes, F. de S (2001). Estudo da erodibilidade e parâmetros geotécnicos de um solo em processo erosivo. Dissertação (Mestrado em Engenharia Civil). Centro de Tecnologia e Geociências, Universidade Federal de Pernambuco, Recife, PE, Brasil. 
Gurgel, R. S., Carvalho Júnior, O. A. de C., Gomes, R. A. T., Guimarães, R. F., Câmara, J. F. A., Sobrinho, D. A., Martins, E. de S., \& Braga, A. R. dos S. (2011). Identificação das áreas vulneráveis à erosão a partir do emprego da EUPS - equação universal de perdas de solos no município de Riachão das Neves - BA. Geografia Ensino \& Pesquisa, 15 (3), 93-112. http://dx.doi.org/10.5902/223649947348

IJSN - Instituto Jones dos Santos Neves. (2020). Shapefiles. Recuperado 11 de março de 2020, de http://www.ijsn.es.gov.br/mapas/

Infanti Junior, N., \& Fornasari Filho, N. (1998). Processos de dinâmica superficial. In: ABGE. Geologia de Engenharia. São Paulo. p.131-152.

Lima, G. S. A. de, Ferreira, N. C., \& Ferreira, M. E. (2018). Modelagem da Perda Superficial de Solo para Cenários de Agricultura e Pastagem na Região Metropolitana de Goiânia. Revista Brasileira de Cartografia, 70 (4), 1510-1536.

Lombardi Neto, F., \& Moldenhauer, W. C. (1992). Erosividade da chuva: sua distribuição e relação com as perdas de solo em Campinas (SP). Bragantia, 51 (2), 189-196.

Macedo, M. A., \& Ruddorf, B. F. T. (2000). Estimativa da perda de solo por erosão laminar na bacia do Rio São Bartolomeu-DF usando técnicas de geoprocessamento. Recuperado 23 de fevereiro de 2020, de http://www.dpi.inpe.br/cursos/ser300/Trabalhos/mariza.pdf

Maciel, M. M. (2000). Aplicação da Equação Universal de Perdas de Solo (USLE) em ambiente de geoprocessamento e sua comparação com aptidão agrícola. Dissertação (Mestrado em Agronomia - Ciência do Solo). Setor de Ciências Agrárias da Universidade Federal do Paraná, Curitiba, PR, Brasil.

Martins, S. G. et al. (2010). Fator cobertura e manejo do solo e perdas de solo e água em cultivo de eucalipto e em Mata Atlântica nos Tabuleiros Costeiros do estado do Espírito Santo. Scientia Forestalis, 38(87), 517-526.

Mata, C. L., Carvalho Júnior, O. A. de, Carvalho, A. P. F. de, Gomes, R. A. T., Martins, E. de S., \& Guimarães, R. F. (2007). Avaliação multitemporal da susceptibilidade erosiva na bacia do Rio Urucuia (MG) por meio da Equação Universal de Perda de Solos. Revista Brasileira de Geomorfologia, 8(2), 57-71. http://dx.doi.org/10.20502/rbg.v8i2.94

Mccool, D. K., Brown, L. C., \& Foster, G. R. (1987). Revised slop steepness factor of the Universal Soil Loss Equation. Transactions of the American Society of Agricultural Engineers, 30, 1387-1396.

Mccool, D. K., Foster, G. R., Mutchler, C. K., \& Meyer, L. D. (1989). Revised slope length factor for the Universal Soil Loss Equation. Transactions of the American Society of Agricultural Engineers, 32, 1571-1576.

Miqueloni, D. P., Bueno, C. R. P., \& Ferraudo, A. S. (2012). Análise espacial dos fatores da equação universal de perda de solo em área de nascentes. Pesquisa Agropecuária Brasileira, 47(9), 1358-1367. https://doi.org/10.1590/S0100204X2012000900021

Mota, S. (1981). Planejamento urbano e preservação ambiental. Fortaleza: Edições UFC.

Pedro, F. G., \& Lorandi, R. (2004). Potencial natural de erosão na área periurbana de São Carlos-SP. Revista Brasileira de Cartografia, 1(56), 28-33.

Pereira, M. R. D., Santos, A. A. dos, \& Sousa, S. B. de (2017). Aplicação da Equação Universal de Perda de Solo (EUPS) na previsão a erosão hídrica na bacia hidrográfica do Córrego Francisquinha - Porto Nacional - TO. Revista Tocantinense de Geografia, 6(10): 100-112. https://doi.org/10.20873/uft.2317-9430.2017v6n10p100

Pinheiro, L. de S., \& Cunha, C. M. L. da (2011). A importância da geração do fator topográfico (LS) da EUPS para modelagem erosiva de bacia bidrográfica. Recuperado 8 de abril de 2020, de https://www.revistas.una.ac.cr/index.php/geografica/article/view/2585/2469

Ribaski, J., Dedecek, R. A., Mattei, V. L., Flores, C. A., Vargas, A. F. C., \& Ribaski, S. A. G. (2005). Sistemas silvipastoris: estratégias para o desenvolvimento rural sustentável para a metade Sul do Estado do Rio Grande do Sul. Colombo: Embrapa Florestas, 8 p.

Santos, A. R. dos., Louzada, F. L. R. de O., \& Eugênio, F. C. (2010). ArcGIS 9.3 total: aplicações para dados espaciais. 2.ed. Alegre: CAUFES. 184 p.

Silva, R. M., Paiva, F. M. de L., \& Santos, C. A. G. (2009). Análise do grau de erodibilidade e perdas de solo na bacia do Rio Capiá baseado em SIG e sensoriamento remoto. Revista Brasileira de Geografia Física, 2(1), $26-40$. https://doi.org/10.26848/rbgf.v2.1.p26-40

Souza, V. de, \& Gasperetto, N. V. L. (2012). Aplicação da Equação Universal de Perdas de Solo (EUPS) na bacia do 
Córrego Pinhalzinho Segundo, noroeste do Paraná. Revista Brasileira de Geomorfologia, 13(3), $267-278$. http://dx.doi.org/10.20502/rbg.v13i3.191

Pereira, J. S. (2014). Avaliação das perdas de solos por erosão laminar na área de influência da UHE Amador Aguiar I. Dissertação (Mestrado em Geografia). Programa de Pós Graduação em Geografia da Universidade Federal de Uberlândia, Uberlândia, MG, Brasil.

Silva, V. C. (2004). Estimativa da erosão atual da bacia do Rio Paracatu (MG/GO/DF). Pesquisa Agropecuária Tropical, 34(3): 147-159.

Silva, M. J. dos S. O., Silva Filho, J. A., \& Silva, A. J. L. (2015). Principais impactos e mudanças na paisagem decorrentes da ocupação desordenada no município de Encanto - RN: exemplo do bairro Alto da Boa Vista. Revista do CERES, 1(2), 115-1221.

Stein, D. P., Donzelli, P. L., Gimenez, F. A., Ponçano, E. L., \& Lombardi Neto, F. (1987). Potencial de erosão laminar, natural e antrópico na Bacia do Peixe-Paranapanema. In: Anais do IV Simpósio Nacional de Controle de Erosão. Marília, SP, Brasil.

Wischmeier, W. H., \& Smith, D. D. (1978). Predicting rainfall erosion losses: a guide to conservation planting. Washington: USDA, $58 \mathrm{p}$. 